\title{
IDENTIFIKASI KAYU PERAHU KUNA SITUS PUNJULHARJO REMBANG JAWA TENGAH
}

\author{
Widyanto Dwi Nugroho ${ }^{1,2)}$ \\ 1) Laboratorium Struktur dan Sifat Kayu, Jurusan Teknologi Hasil Hutan, \\ Fakultas Kehutanan, Universitas Gadjah Mada, e-mail: wdnugroho@ugm.ac.id \\ 2) Mahasiswa Program Doktor di Tokyo University of Agriculture and Technology, \\ Jepang.
}

\begin{abstract}
Indonesia is a country with a rich maritime history. The finding of ancient wooden ark in Punjulharjo site, Rembang, Central Java that was ascribed to seventh century A.D., was a proof of the growth of the ancient maritime culture. This finding needs some support to find out the origin of the ark. This research was intended to identify the wood species used on board, stringer and dowel part. The identification result was expected to be useful to estimate the origin of the wooden ark.

The wood identification process was done by observing the wood anatomy on the board, stringer and the dowel part using loupe and light microscopy. The identification result showed that according to its wood's characteristic, the board part of the ark was predicted as wood from the family Sapotaceae, genus Palaquium, and species Palaquium spp. (Nyatoh Wood); wood used as stringer part was estimated as wood from the family of Olacaceae, family Scorodocarpus and species Scorodocarpus bomesis (Kulim Wood) and the wood used as dowel part was estimated as wood from the family Myrtaceae, genus Melaleuca and species Melaleuca leucadendron (Cajuput Wood).

Based on the natural distribution of species used as component making of the ark, it was estimated that the ark was originated from Indonesian archipelago, specifically Sumatra island, Borneo island or Malay Peninsula.
\end{abstract}

Key words: Kayu, Identifikasi, Anatomi, Perahu Kuna, Situs Punjulharjo

\section{PENDAHULUAN}

Indonesia diperkirakan memiliki 3000 situs yang mengandung sumberdaya arkeologi bawah air sebagai bukti kejayaannya di bidang maritim (Noerwidi, 2007). Jejak kejayaan Indonesia sebagai wilayah yang unggul dalam tradisi bahari dapat dilihat pada beberapa peninggalan sejarah, antara lain relief perahu di Candi Borobudur, lukisan-lukisan perahu pada dinding gua di beberapa tempat di Indonesia, cerita sejarah tentang kejayaan Nusantara di bidang maritim serta temuan-temuan fisik bebarapa 
bangkai perahu yang diduga berasal dari masa-masa tersebut. Salah satu contohnya adalah temuan bangkai perahu di situs Kota Kapur yang merupakan lokasi penting pada masa kejayaan Kerajaan Sriwijaya sebagaimana disampaikan Rangkuti (2007) dalam tulisannya di media massa nasional pada 25 September 2007.

Penemuan penting terakhir jejak kejayaan kebaharian Indonesia adalah sisa-sisa perahu kuna di Situs Punjulharjo, Rembang, Jawa Tengah. Perahu kuna ini ditemukan pada akhir Agustus 2008 pada lokasi tambak garam, kurang lebih $1 \mathrm{~km}$ sebelah selatan garis pantai. Bangkai perahu kuna yang masih relatif utuh ini adalah bukti yang diharapkan bisa berkisah tentang sejarah kebaharian suatu bangsa atau kerajaan tertentu yang sekaligus mencerminkan tingkat kemajuan budaya maupun teknologi maritim pada masa itu.

Temuan perahu kuna di Situs Punjulharjo ini seakan menjadi misteri yang cukup menantang untuk diungkap, khususnya mengenai identitas perahu tersebut, sehingga bisa dirangkai dalam untaian sejarah kebaharian Nusantara. Diperlukan penelitian tuntas dan upaya pelestarian terhadap temuan ini agar warisan budaya ini dapat mengungkap sejarah kebaharian pada masanya. Dukungan dan kerjasama antara berbagai disiplin ilmu dalam mengkaji temuan ini akan semakin memperkuat analisis dalam rangka mengungkap identitas temuan.

Salah satu disiplin ilmu yang dapat mendukung bidang arkeologi ialah IImu kayu. Peranan ilmu kayu dalam menganalisa temuan arkeologi dapat berupa proses identifikasi kayu untuk menentukan jenis dan asal-usul kayu, proses karakterisasi bahan kayu dalam menentukan sifat-sifat kayu yang ditemukan, proses pengawetan kayu dalam upaya konservasi temuan tersebut serta proses rekayasa bahan untuk merekontruksi bentuk asli suatu temuan. Penelitian tentang kayu yang terkait dengan bidang arkeologi antara lain dilakukan untuk mengidentifikasi temuan-temuan bahan kayu yang sudah menjadi arang peninggalan tahun 1200-an dari Mexico (Angeles, 2001), identifikasi kayu plafon peninggalan abad ke-12 di situs Cappella Palatina Palermo Itali (Romagnoli et al. 2007), identifikasi lembaran kayu kapal karam di Ulu Burun, Turki (Pendleton dan Warnock, 1990) serta beberapa penelitian lain termasuk identifikasi kayu perahu kuna yang ditemukan di Bengawan Solo, Bojonegoro (Siagian dan Nugroho, 2007).

Perahu kuna yang ditemukan di Situs Punjulharjo, Rembang, hampir seluruh bagian-bagiannya merupakan komponen yang berasal dari kayu. Asal-usul kayu yang digunakan sebagai bahan perahu bisa dijadikan kunci untuk menduga asal-usul perahu tersebut. Setiap spesies pohon (kayu) memiliki persebaran alami. Identitas kayu yang digunakan sebagai komponen perahu bisa ditelusuri asal-usulnya dari persebaran alami spesies kayu tersebut. Penelitian ini dilakukan untuk mengidentifikasi jenisjenis kayu pada bagian papan, stringer dan pasak pada temuan perahu kuna situs Punjulharjo, Rembang, Jawa Tengah. Hasil identifikasi ini 
diharapkan dapat digunakan untuk menduga asal-usul perahu kuna tersebut.

\section{BAHAN DAN METODE}

\section{Bahan}

Bahan yang digunakan dalam penelitian ini adalah kayu-kayu pada bagian papan, stringer, dan pasak perahu kuna situs Punjulharjo, Rembang, Jawa Tengah. Bahan penelitian ini diperoleh dari pengambilan sampel kayu yang dilakukan oleh Balai Arkeologi Yogyakarta. Kondisi sampel yang diperoleh ini dalam keadaan rapuh dan sudah sangat lunak, terutama pada kayu bagian papan.

Selain bahan diatas dalam penelitian ini juga digunakan bahan kimia dalam proses pembuatan preparat. Bahan-bahan kimia yang digunakan adalah Alkohol $\left(\mathrm{C}_{2} \mathrm{H}_{5} \mathrm{OH}\right)$, Safranin, Silol $\left(\mathrm{C}_{5} \mathrm{H}_{10}\right)$, air suling dan balsam kanada.

\section{Pembuatan Contoh uji}

Contoh uji diperoleh dengan memotong sampel kayu-kayu pada bagian papan, stringer, dan pasak perahu kuna situs Punjulharjo, Rembang, Jawa Tengah. Bahan penelitian ini diperoleh dari pengambilan sampel kayu yang dilakukan oleh Balai Arkeologi Yogyakarta.

Pengamatan anatomi kayu secara makroskopis dilakukan pada sampel-sampel kayu yang diperoleh dari Balai Arkeologi Yogyakarta. Selain pengamatan terhadap sampel kayu secara utuh tersebut, dilakukan juga pengamatan dengan membuat contoh uji. Contoh uji untuk pengamatan anatomi kayu secara makroskopis dilakukan dengan membuat potongan kayu dengan ukuran $2 \times 2 \times 2 \mathrm{~cm}$, sedangkan untuk pengamatan pada bagian pasak digunakan contoh uji dengan ukuran $1 \times 1 \times 1 \mathrm{~cm}$ masing-masing sebanyak 3 kali ulangan. Hal ini dilakukan karena sampel utuh yang diperoleh kondisinya sudah cukup lapuk dan lunak sehingga tidak diperoleh penampang yang dapat diamati secara optimal. Pengamatan anatomi kayu secara makroskopis pada contoh uji yang dibuat dilakukan pada saat kayukayu tersebut mulai mengalami penyusutan dimana diperkirakan kayu-kayu tersebut pada kondisi titik jenuh serat (TJS). Pengamatan secara makroskopis dilakukan dengan menggunakan kaca pembesar dengan perbesaran $10 \mathrm{X}$.

Pengamatan struktur kayu secara mikroskopis dilakukan dengan menyiapkan contoh uji dengan ukuran $1 \times 1 \times 1 \mathrm{~cm}$ yang merupakan contoh uji yang sama dengan contoh uji pengamatan makroskopis kayu yang telah diamati. Potongan kayu tersebut kemudian diiris dengan mikrotom pada penampang melintang dan tangensialnya dengan ketebalan 10 - 20 mikron. Irisan yang terbaik (tipis dan tidak sobek) direndam dalam alkohol agar terbebas dari air kemudian diberi zat wama. Selanjutnya irisan tersebut dicelupkan ke dalam silol untuk menghilangkan sisa alkohol dan gelembung 
udara yang ada, kemudian diletakkan pada objek glass, dihangatkan, dan ditutup dengan deck glass (kaca penutup). Preparat yang sudah jadi diletakkan diatas meja objek mikroskop dan dilakukan pemotretan dilanjutkan dengan analisis gambar mikroskopisnya. Pengamatan secara mikroskopis ini menggunakan mikroskop fluoresence Olympus BX 51 dan analisa gambar dilakukan dengan software Image Pro Plus versi 4.5. (Nugroho et al. 2005).

\section{Parameter pengamatan}

Pengamatan struktur kayu yang dilakukan secara makroskopis maupun mikroskopis bertujuan untuk mengumpulkan informasi yang terkait dengan parameter pengamatan yang akan digunakan dalam identifikasi kayu. Adapun parameter yang diamati adalah: lingkaran tahun, sel pembuluh, sel parenkim longitudinal, jari-jari kayu, tekstur kayu, serat kayu, keberadaan saluran getah dan lain-lain ciri struktur yang khas mengacu pada daftar ciri-ciri identifikasi kayu keras IAWA (IAWA Committee 1989).

Data yang diperoleh dari pengamatan tersebut kemudian dibandingkan dengan basis data struktur anatomi kayu untuk identifikasi. Basis data yang digunakan adalah data struktur anatomi kayu dari Anatomy of The Dicotyledons Volume I dan Volume II (Metcalfe \& Chalk, 1950), Identification of the Timber of Southeast Asia and the Western Pacific (Ogata et al. 2008), Csiro Atlas of Hardwoods (llic, 1950), Tropical Timbers Database versi digital (Kikata et al. 2002), Prosea Timber Trees versi digital (Prosea CD-Room), Seri Manual: Pedoman Identifikasi Kayu di Lapangan (Mandang \& Pandit, 1997), Tumbuhan Berguna Indonesia Jilid III (Heyne, 1987) serta koleksi struktur anatomi kayu Laboratorium Struktur dan Sifat Kayu Jurusan Teknologi Hasil Hutan, Fakultas Kehutanan UGM.

\section{HASIL DAN PEMBAHASAN}

\section{A. Identifikasi kayu}

\section{Struktur anatomi kayu komponen perahu: kayu bagian papan}

Secara makroskopis, ciri-cir kayu bagian papan ini sudah sangat sulit untuk dikenali karena kondisinya yang sudah sangat rapuh, lunak sehingga tidak memungkinkan untuk dibuat contoh uji sayatan pengamatan makroskopis. Secara mikroskopis, kayu diamati pada tiga penampang utama kayu yaitu penampang melintang (transversal), penampang tangensial dan penampang radial kayu. Gambar tiga penampang kayu secara mikroskopis pada kayu bagian papan ini disajikan dalam gambar 13. Adapun hasil pengamatan yang dilakukan terhadap kayu bagian papan ini adalah sebagai berikut.

1. Lingkaran tahun: lingkaran tahun tidak nampak pada kayu ini.

2. Pembuluh: ada pembuluh dengan tipe sebaran tunggal, ganda radial (2- 
3 sel) dan beberapa pembuluh berkelompok. Pada beberapa pembuluh ditemukan adanya tilosis.

3. Parenkim: pita sempit (narrow bands)

4. Jari-jari kayu: terdapat jari-jari kayu yang nampak pada penampang $x, t$ dan $r$. Pada penampang $x$ dan $t$ hanya terdapat 1 macam ukuran sel jarijai berseri 1. Tinggi jari-jari kayu antara 300-500 mikron. Pada penampang $t$, jari-jari tidak bertingkat.

5. Tekstur: tidak diketahui tekstur asli dari kayu ini, namun diperkirakan kayu ini memiliki tekstur yang halus.

6. Serat: lurus sampai agak bergelombang.

7. Salurah getah: tidak ditemukan adanya saluran getah dalam kayu ini.

8. Ciri struktur yang khas lainnya: bidang perforasi pada pembuluh adalah bidang perforasi sederhana. Diameter pembuluh 50-150 mikron.

Berdasar atas ciri-ciri struktur anatomi kayunya, kayu ini diduga merupakan kayu dari Suku Sapotaceae, Marga Palaquium, Spesies Palaquium spp. Kayu Palaquium spp. ini dikenal dengan nama perdagangan atau nama lokal kayu Nyatoh. Kayu dari marga Palaquium ini terdiri dari 110 spesies (Prosea CD-Room). Dari anatomi kayunya, spesies yang paling mendekati ciri-ciri struktur anatomi kayu ini ialah species Palaquium gutta.

Penggunaan kayu Palaquium gutta ini sebagai papan kayu pada perahu kuna Situs Punjulharjo ini cukup beralasan. Prosea memaparkan bahwa Palaquium gutta menghasilkan getah yang disebut Gutta-percha. Gutta-percha dinyatakan unggul sebagai bahan isolator dan kedap air. Hal ini juga dimungkinkan mempengaruhi sifat kayunya sebagai bahan yang kedap air. Sifat sebagai bahan yang kedap air inilah yang mungkin menjadi pertimbangan pembuat perahu pada masa itu untuk menggunakan kayu ini sebagai bagian utama pembuatan perahu.

\section{Struktur anatomi kayu komponen perahu: kayu bagian stringer}

Kayu pada bagian stringer perahu kuna Situs Punjulharjo ini tidak serapuh kayu pada bagian papan. Pengamatan secara makroskopis masih bisa dilakukan walaupun informasi yang bisa dihimpun sudah sangat sedikit. Kayu ini diamati pada tiga penampang utama kayu yaitu penampang melintang (transversal), penampang tangensial dan penampang radial kayu. Gambar tiga penampang kayu secara mikroskopis pada kayu bagian pasak ini berturut-turut disajikan dalam gambar 4-6 dan hasil pengamatan yang dilakukan terhadap kayu bagian papan ini adalah sebagai berikut.

1. Lingkaran tahun: lingkaran tahun terlihat jelas yang ditandai dengan distribusi pembuluh yang lebih banyak pada kayu awal.

2. Pembuluh: ada pembuluh dengan susunan pori tata lingkar semu, tipe sebaran didominasi oleh pembuluh bersebaran ganda radial ( $2-5$ sel), terdapat juga pembuluh tunggal. Tidak ditemukan pembuluh yang berisi tilosis.

3. Parenkim: diffuse aggregate

Berkala Arkeologi Tafun XXIX Edisi No. 2 /November 2009 
4. Jari-jari kayu: terdapat jari-jari kayu yang nampak pada penampang $x, t$ dan $r$. Pada penampang $x$ dan thanya terdapat 1 macam ukuran sel jarijai berseri 1. Susunan jari-jari heteroseluler. Tinggi jari-jari kayu antara $300-700$ mikron. Pada penampang $t$, jari-jari tidak bertingkat.

5. Tekstur: tidak diketahui tekstur asli dari kayu ini, namun diperkirakan kayu ini memiliki tekstur yang halus.

6. Serat: lurus sampai agak bergelombang.

7. Salurah getah: tidak ditemukan adanya saluran getah dalam kayu ini.

8. Ciri struktur yang khas lainnya: bidang perforasi pembuluh adalah bidang perforasi scaliform. Diameter pembuluh 70-120 mikron.

Anatomi kayu di atas mencirikan kayu ini merupakan kayu dari Suku Olacaceae Marga Scorodocarpus. Kayu ini diduga adalah kayu Kulim yang dikenal dengan nama botani Scorodocarpus Borneensis.

Kayu Kulim dikenal sebagai kayu yang baik digunakan untuk konstruksi sedang maupun konstruksi berat diantaranya sebagai bahan pembuatan gelagar, balok, tonggak, pintu, jendela, lantai, bangunan jembatan, lunas kapal maupun bantalan rel kereta api. Martawijaya et al. (1989) menyebutkan bahwa kayu Kulim merupakan kayu yang potensial sebagai bahan kusen pintu rumah dan kapal kayu terutama bagian dinding/palka kapal dan tiang kapal. Informasi ini menguatkan dugaan bahwa kayu yang digunakan sebagai komponen stringer perahu kuna Situs Punjulharjo adalah kayu Kulim. Dilaporkan bahwa kayu Kulim mulai sulit ditemukan keberadaannya (Heriyanto N.M.\& Garsetiasih R. 2004).

\section{Struktur anatomi kayu komponen perahu: kayu bagian pasak}

Kayu bagian pasak ini sudah cukup sulit untuk dilakukan pengamatan secara makroskopis. Sebagaimana pengamatan mikroskopis pada kayu bagian papan maupun stringer, kayu ini diamati pada tiga penampang utama kayu yaitu penampang melintang (transversal), penampang tangensial dan penampang radial kayu. Gambar tiga penampang kayu secara mikroskopis pada kayu bagian pasak ini berturutturut disajikan dalam gambar 7-9. Adapun hasil pengamatan yang dilakukan terhadap kayu bagian papan ini adalah sebagai berikut.

1. Lingkaran tahun: lingkaran tahun terlihat jelas yang ditandai dengan distribusi pembuluh yang lebih banyak pada kayu awal.

2. Pembuluh: ada pembuluh dengan susunan pori tata lingkar semu, tipe sebaran didominasi oleh pembuluh bersebaran tunggal. Tidak ditemukan pembuluh yang berisi tilosis.

3. Parenkim: konfluen pita sempit dan pendek (short narrow banded confluent)

4. Jari-jari kayu: terdapat jari-jari kayu yang nampak pada penampang $x, t$ dan $r$. Pada penampang $x$ dan thanya terdapat 2 macam ukuran sel jarijai berseri banyak. Tinggi jari-jari kayu antara 150-500 mikron. Pada penampang $t$, jari-jari tidak bertingkat.

5. Tekstur: tidak diketahui tekstur asli dari kayu ini, namun diperkirakan 
kayu ini memiliki tekstur yang halus.

6. Serat: lurus sampai bergelombang.

7. Salurah getah: tidak ditemukan adanya saluran getah dalam kayu ini.

8. Ciri struktur yang khas lainnya: bidang perforasi pada pembuluh adalah bidang perforasi sederhana. Diameter pembuluh 25-150 mikron.

Berdasar atas ciri-ciri struktur anatomi kayunya, kayu pada bagian pasak perahu kuna Situs Punjulharjo ini diduga merupakan kayu dari Suku Myrtaceae, Marga Melaleuca, Spesies Melaleuca leucadendron. Nama daerah dari species Melaleuca leucadendron ini adalah kayu putih.

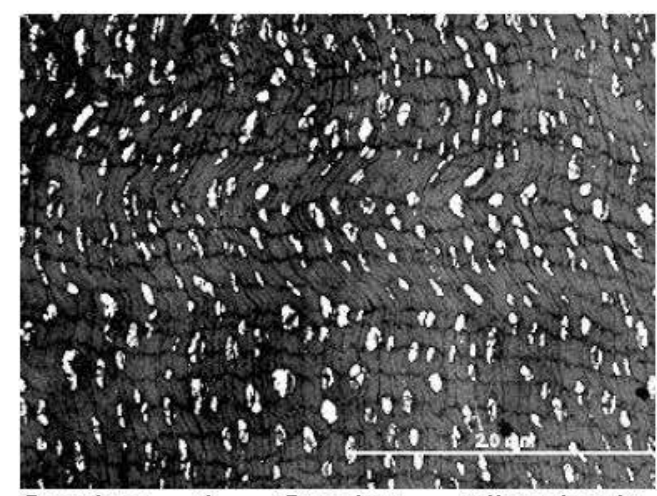

Gambar 1. Gambar mikroskopis penampang transversal kayu papan.

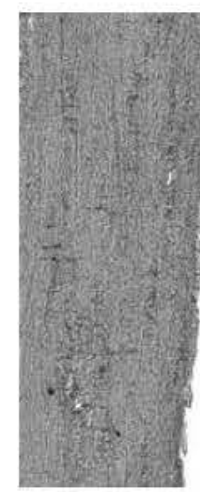

Gambar 3. Gambar mikroskopis penampang radial kayu papan.

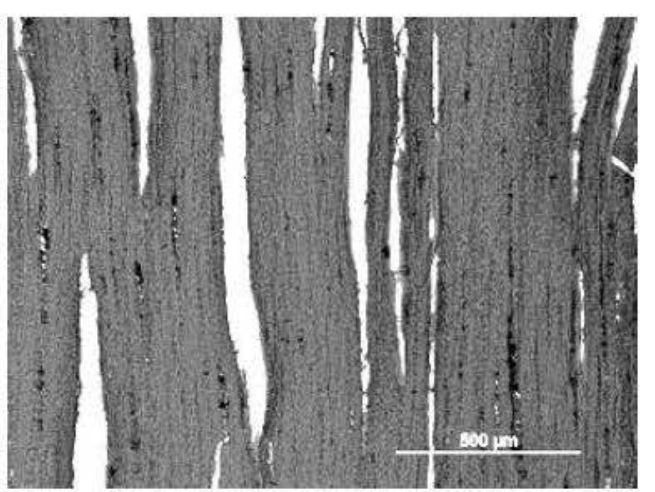

Gambar 2. Gambar mikroskopis penampang tangensial kayu papan.

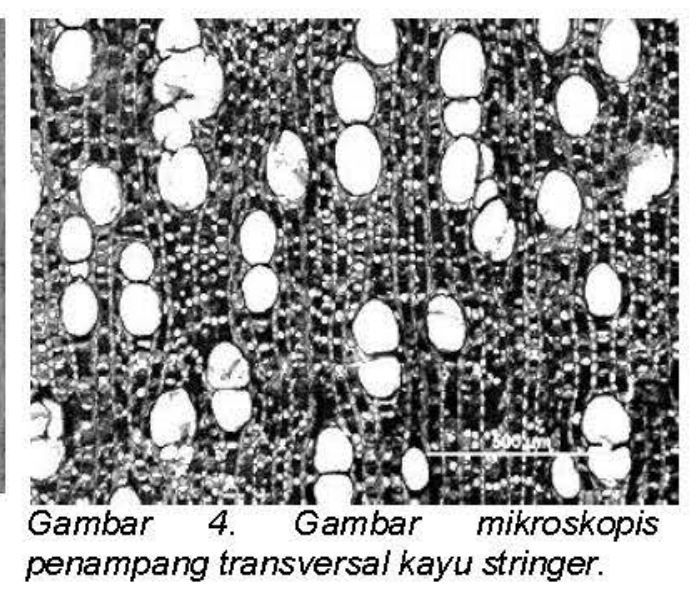




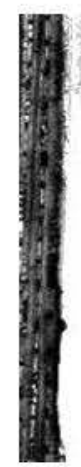

Gambar penampang tangensial kayu stringer.

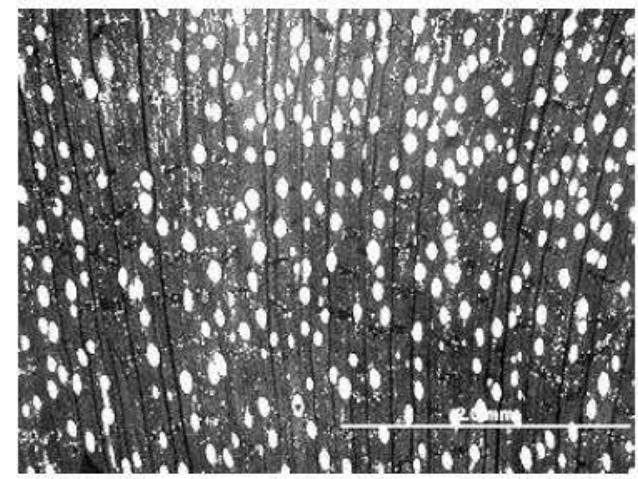

Gambar 7. Gambar mikroskopis penampang transversal kayu pasak.

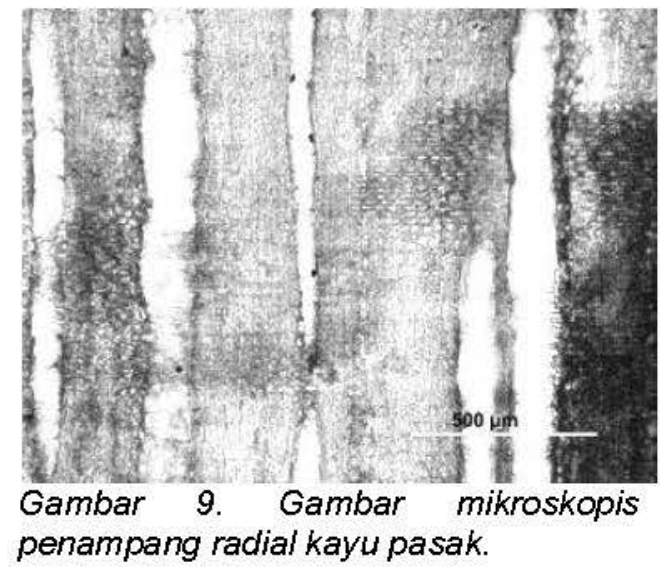

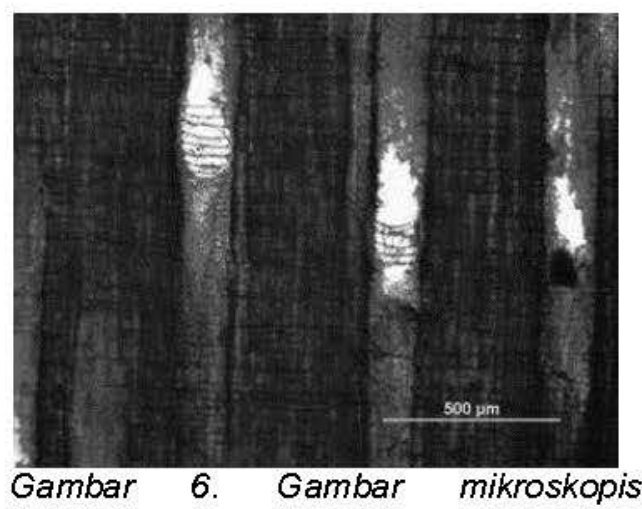
penampang radial kayu stringer.

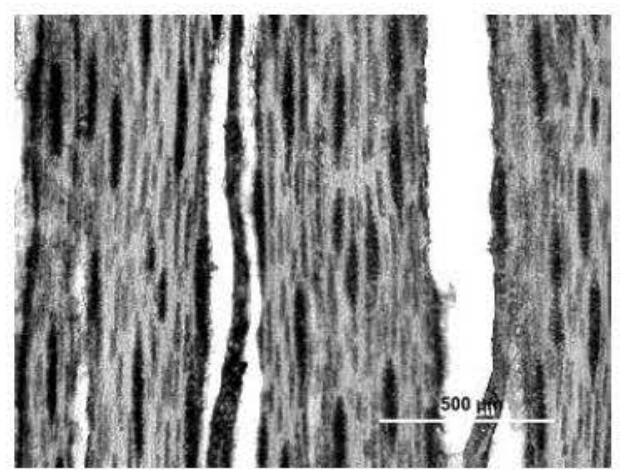

Gambar 8. Gambar mikroskopis penampang tangensial kayu pasak. 


\section{B. Menduga asal-usul perahu dari persebaran alami}

kayu yang digunakan

\section{Kayu bagian papan (Palaquium spp.)}

Kayu bagian papan diduga merupakan kayu dari spesies Palaquium spp., dan diduga merupakan spesies Palaquium gutta. Semua species kayu dari Genus palaquium dikenal dengan nama kayu Nyatoh. Kayu nyatoh terdiri dari 115 spesies yang tersebar di wilayah Asia Tenggara sampai dengan Pasifik Barat. Hampir semua jenis kayu Nyatoh tumbuh di hutan dataran rendah. Banyak jenis kayu Nyatoh yang bisa ditemukan tumbuh pada hutan gambut. Prosea menyebutkan bahwa persebaran alami dari kayu Palaquium gutta ini adalah Semenanjung Malaysia, Singapura, Sumatera dan Kalimantan. Peta sebaran alami kayu Palaquium gutta disajikan dalam gambar 10 .

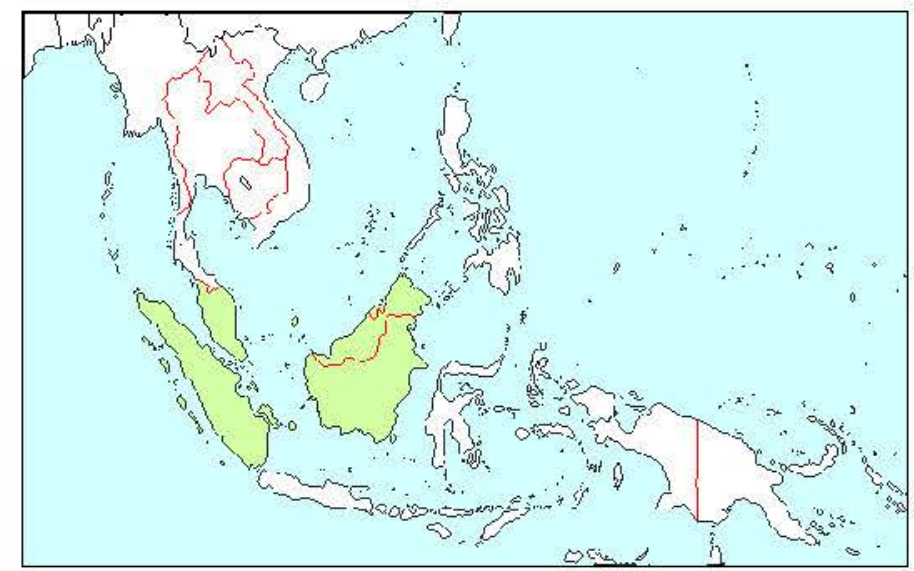

Gambar 10. Peta sebaran alami kayu Palaquium gutta, yaitu di Semenanjung Malaysia, Singapura, Sumatera dan Kalimantan. (sumber gambar: Prosea Cdroom version).

\section{Kayu bagian stringer (Scorodocarpus borneensis)}

Kayu bagian stringer diduga merupakan kayu dari spesies Scorodocarpus borneensis. Genus Scorodocarpus merupakan genus yang monotipik atau hanya terdiri dari 1 spesies saja. Ogata K. et al. (2008) menyebutkan bahwa kayu yang dikenal dengan nama kayu Kulim ini tesebar secara alami di dataran rendah Malaya, Sumatera dan Bomeo. Hal ini diperkuat oleh keterangan yang disampaikan oleh Prosea bahwa asal dan distribusi wilayah kayu Scorodocarpus mencakup wilayah Semenanjung Thailand, Semenanjung Malaysia, Sumatera dan Kalimantan (Prosea CD-Room). Scorodocarpus borneensis tumbuh menyebar dan kadang-kadang tumbuh mengelompok di hutan tropis primer sampai pada ketinggian 600 atau 900 meter dpl. Peta sebaran alami kayu Scorodocarpus bomeensis disajikan dalam gambar 11. 


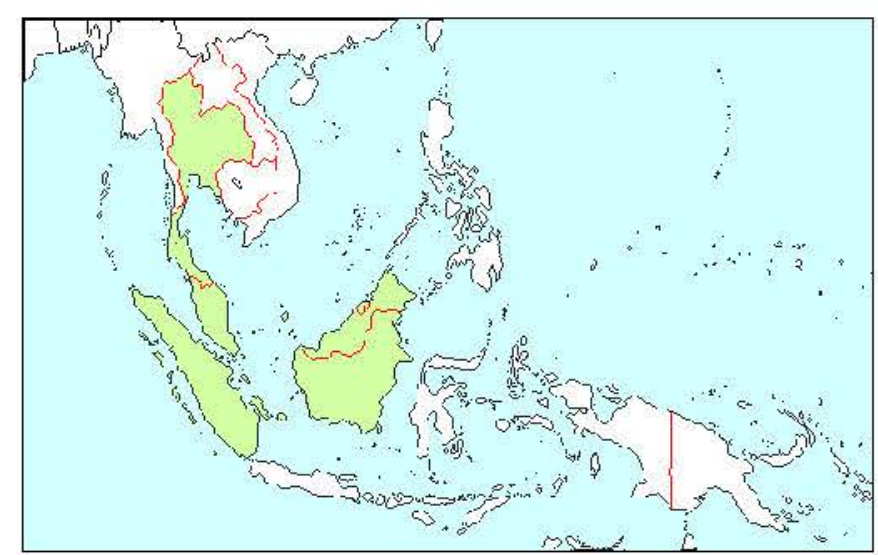

Gambar 11. Peta sebaran alami kayu Scorodocarpus borneensis, yaitu di

Semenanjung Thailand, Semenanjung Malaysia, Sumatera dan Kalimantan (sumber gambar: Prosea Cd-room version).

\section{Kayu bagian pasak (Melaleuca leucadendron)}

Dari hasil identifikasi, kayu bagian pasak ini diduga merupakan kayu dari Suku Myrtaceae Marga Melaleuca Spesies Melaleuca leucadendron yang dikenal juga dengan nama lain Kayu Putih. Marga Melaleuca hanya terdapat di Australia kecuali satu spesies yaitu Melaleuca leucadendron. Melaleuca leucadendron mempunyai distribusi alami di wilayah Asia Tenggara, New Guinea, Australia and New Caledonia (Ogata K. 2008). Pohon ini biasanya tumbuh di hutan rawa gambut berbatasan dengan hutan mangrove.

Berdasarkan atas analisa struktur anatomi kayunya, kayu ini memiliki pola lingkaran pertumbuhan yang jelas. Dari pola lingkaran pertumbuhan yang terlihat jelas ini bisa diduga bahwa kayu ini berasal dari daerah yang memiliki perubahan kondisi tempat tumbuh yang cukup berbeda. Diduga kayu ini tumbuh di lahan gambut atau rawa gambut yang mengalami pola perubahan lingkungan pasang surut. Kondisi rawa gambut yang mengalami pola perubahan lingkungan pasang surut banyak dijumpai di Pulau Sumatera maupun Kalimantan.

\section{Asal-usul perahu kuna Situs Punjulharjo}

Asal-usul suatu barang bisa ditelusuri dari asal-usul bahan yang digunakan sebagai penyusun barang tersebut. Demikian juga dengan temuan perahu kuna di Situs Punjulharjo ini. Setelah diketahui identitas kayu-kayu yang menjadi penyusun atau komponen perahu selanjutnya bisa diketahui persebaran alami jenis-jenis kayu tersebut. Kayu Nyatoh memiliki persebaran alami meliputi Semenanjung Malaysia, Singapura, Sumatera dan Kalimantan. Kayu Kulim memiliki persebaran alami di Semenanjung Thailand, Semenanjung Malaysia, Sumatera dan Kalimantan, sedangkan Kayu putih yang digunakan diduga dari wilayah yang kurang lebih sama dengan kedua kayu lainnya. 
Dari data yang diperoleh dan analisa yang dilakukan dapat ditarik benang merah yang cukup jelas bahwa perahu kuna yang ditemukan di Desa Punjulharjo, Kecamatan Kota Rembang, Kabupaten Rembang, Jawa Tengah ini merupakan perahu Nusantara yang berasal dari wilayah Sumatera, Kalimantan atau Semenanjung Malaysia. Data pendukung mengenai umur perahu, tipe perahu, teknologi pembuatan perahu, temuantemuan pembanding maupun ciri-ciri lain yang khas pada perahu diperlukan untuk mencari asal-usul perahu kuna ini secara lebih detail. Dengan data yang lengkap maka dimungkinkan dapat disimpulkan dari suatu masyarakat atau kerajaan tertentu dimana perahu ini berangkat mengarungi laut dan akhirnya terdampar di Rembang.

\section{KESIMPULAN}

1. Hasil dari identifikasi ini menunjukkan bahwa berdasar atas ciri-ciri struktur anatomi kayunya, kayu bagian papan ini diduga merupakan kayu dari Suku Sapotaceae Marga Palaquium Spesies Palaquium spp. (kayu Nyatoh), kayu bagian stringer diduga merupakan kayu dari Suku Olacaceae Marga Scorodocarpus Spesies Scorodocarpus bomeensis (kayu Kulim) dan kayu bagian pasak diduga merupakan kayu dari Suku Myrtaceae Marga Melaleuca Spesies Melaleuca leucadendron (Kayu Putih).

2. Berdasar atas data sebaran jenis-jenis kayu yang digunakan sebagi komponen pembuatan perahu tersebut, perahu diperkirakan berasal dari wilayah Nusantara lebih khususnya dari wilayah Sumatera, Kalimantan atau Semenanjung Malaysia.

\section{Saran}

Temuan perahu kuna di situs Punjulharjo merupakan kekayaan budaya yang sangat berharga. Penelitian identifikasi kayu perahu kuna situs Punjulharjo ini masih merupakan penelitian dalam taraf pendahuluan. Penelitian lanjutan yang lebih detail dan menyeluruh terhadap temuan ini sangat diperlukan untuk mengungkap sejarah perahu kuna tersebut sekaligus untuk mengetahui cara terbaik untuk mengkonservasi temuan tersebut dengan pertimbangan bahwa kayu-kayu bagian perahu kuna sudah sangat rapuh. Diperlukan penanganan yang tepat agar bagian-bagian kayu tersebut tidak rusak. Saran lainnya ialah upaya penelitian secara menyeluruh dari berbagai disiplin ilmu sebaiknya dilakukan pada berbagai temuan-temuan serupa sehingga bisa dicari benang merah sejarah perkembangan budaya maritim Nusantara dengan lebih akurat. 


\section{Ucapan Terima Kasih:}

Penulis menyampaikan terima kasih kepada Bapak Drs. Siswanto (Kepala Balai Arkeologi Yogayakarta), Dra. Novida Abbas (Ketua Tim Peneliti Temuan Perahu Kuna Situs Punjulharjo Rembang) dan Hery Priswanto (Tim Peneliti Temuan Perahu kuna Situs Punjulharjo Rembang) atas ijin, bantuan dan dukungannya dalam penulisan artikel ini.

\section{KEPUSTAKAAN}

Angeles, G. 2001. New Techniques for The Anatomical Study of Charcoalified Wood. IAWA Journal. Vol. 22 (3):245-254.

Heriyanto, N.M. \& Garsetiasih, R. 2004. Potensi Pohon Kulim (Scorodocarpus bomeensis Becc.) di Kelompok Hutan Gelawan Kampar, Riau. Buletin Plasma Nutfah. Vol. 10. No. 1.

Heyne, 1987. Tumbuhan Berguna Indonesia Jilid III. Badan Penelitian dan Pengembangan. Departemen Kehutanan, Jakarta.

IAWA Committee. 1989. IAWA list of microscopic features for hardwood identification. Wheeler, E.A., Baas, P. \& Gasson, P.E., (editor). IAWA Bull. (N.S.). 10. 219-332.

Ilic, J. 1950. Csiro Atlas of Hardwoods. Crawford House Press in Association with Csiro Publications. Melbourne. Australia.

Kikata, Y., Tejada, A. \& Marsoem, S.N. 2002. Tropical Timber Database:The Establishment of The Database of Tropical Industrial Lesser Used Wood Species. CD-room version. ITTO Project PD 5897. Nagoya University Museum.

Mandang, Y.I \& Pandit, I.K.N. 1997. Seri Manual: Pedoman Identifikasi Kayu di Lapangan. Yayasan PROSEA, Bogor \& Pusat Diklat Pegawai \& SDM Kehutanan, Bogor.

Martawijaya, A., Kartasujana, I., Mandang, Y.I., Prawira, S.A., \& Kadir, K. 1989. Atlas Kayu Indonesia Jilid II. Departemen Kehutanan. Badan Penelitian dan Pengembangan Kehutanan. Bogor.

Metcalfe, C.R. \& Chalk, L. 1950. Anatomy of the Dicotyledons-Leaves, stem, and wood in relation to taxonomy with notes on economic uses. Vol. I, II. Oxford at the Clarendon Press. 
Noerwidi, S. 2007. Pemberdayaan Masyarakat pada Pelestarian Situs bangkai Kapal "USS Liberty", Tulamben, Bali. Berkala Arkeologi Tahun XXVII. Edisi No. 1.

Nugroho W.D., Kasmudjo, and Siagian P.B., 2005. Tingkat akurasi pengamatan proporsi sel kayu dengan beberapa metode. Oral presentation. Seminar Mapeki VIII, Kutai Kartanegara. 3-5 September 2005.

Ogata, K. et al. 2008. Identification of The Timbers of Southeast Asia and The Western Pacific. Forestry and Forest Product Institute. Kaiseisha Press. Japan.

Pendleton, M. \& Warnock, P. 1990. Scanning Electron Microscope Aided Wood Identification of A Bronze Age Wooden Diptych. IAWA Bulletin n.s. Vol. 11 (3):255-260.

Prosea CD-room version, Plant Resources of South-East Asia - Timber trees. Hong, L.T., Lemmens, R.H.M.J., Prawirohatmodjo, S., ISoerianegara, I., Sosef, M.S.M. \& Wong, W.C. (editor). ETI and PROSEA.

Rangkuti, N. 2007. Peninggalan Sejarah: Jejak Bahari Kota Kapur. Kompas. Senin 05 November 2007.

Romagnoli, M. et al. 2007. Wood Identification in The Cappella Palatina Ceiling (12 ${ }^{\text {th }}$ Century) in Palermo (Sicily, Italy). IAWA Joumal. Vol. 28 (2): $109-123$

Siagian, B. \& Nugroho, W.D. 2007. Identifikasi Kayu Perahu Kuno yang Ditemukan di Bengawan Solo, Bojonegoro. Poster Penelitian. Laboratorium Struktur dan Sifat Kayu. Jurusan Teknologi Hasil Hutan. Fakultas Kehutanan. UGM. 